\title{
Identification of Serious Adverse Events in Patients with Traumatic Brain Injuries, from Prehospital Care to Intensive-Care Unit, Using Early Warning Scores
}

\author{
Francisco Martín-Rodríguez ${ }^{1,2}{ }^{\oplus}$, Raúl López-Izquierdo ${ }^{3, *(\mathbb{D}}$, Alicia Mohedano-Moriano ${ }^{4}$, \\ Begoña Polonio-López ${ }^{4}\left(\mathbb{D}\right.$, Clara Maestre Miquel ${ }^{4}$, Antonio Viñuela ${ }^{4}(\mathbb{D}$, \\ Carlos Durantez Fernández ${ }^{4}{ }^{\circledR}$, Jesús Gómez Correas ${ }^{4}$, Gonçalo Marques ${ }^{5}{ }^{(D)}$ and \\ José Luis Martín-Conty ${ }^{4}$ (D) \\ 1 Advanced Clinical Simulation Center, School of Medicine, Universidad de Valladolid, 47005 Valladolid, \\ Spain; fmartin@saludcastillayleon.es \\ 2 Advanced Life Support Unit, Emergency Medical Services, 47006 Valladolid, Spain \\ 3 Emergency department, Hospital Universitario Rio Hortega, 47012 Valladolid, Spain \\ 4 Faculty of Health Sciences, Universidad de Castilla la Mancha, 45600 Talavera de la Reina, Spain; \\ Alicia.Mohedano@uclm.es (A.M.-M.); Begona.polonio@uclm.es (B.P.-L.); Clara.maestre@uclm.es (C.M.M.); \\ Antonio.vinuela@uclm.es (A.V.); Carlos.durantez@uclm.es (C.D.F.); jesus.gomez@uclm.es (J.G.C.); \\ JoseLuis.MartinConty@uclm.es (J.L.M.-C.) \\ 5 Instituto de Telecomunicaciones, Universidad de Beira Interior, 6200-001 Covilhã, Portugal; \\ goncalosantosmarques@gmail.com \\ * Correspondence: rlopeziz@saludcastillayleon.es; Tel.: +34-647946325
}

Received: 16 January 2020; Accepted: 25 February 2020; Published: 26 February 2020

\begin{abstract}
Traumatic brain injuries are complex situations in which the emergency medical services must quickly determine the risk of deterioration using minimal diagnostic methods. The aim of this study is to analyze whether the use of early warning scores can help with decision-making in these dynamic situations by determining the patients who need the intensive care unit. A prospective, multicentric cohort study without intervention was carried out on traumatic brain injury patients aged over 18 given advanced life support and taken to the hospital. Our study included a total of 209 cases. The total number of intensive-care unit admissions was 50 cases (23.9\%). Of the scores analyzed, the National Early Warning Score2 was the best result presented with an area under the curve of 0.888 (0.81-0.94; $p<0.001)$ and an odds ratio of 25.4 (95\% confidence interval (CI):11.2-57.5). The use of early warning scores (and specifically National Early Warning Score2) can help the emergency medical services to differentiate traumatic brain injury patients with a high risk of deterioration. The emergency medical services should use the early warning scores routinely in all cases for the early detection of high-risk situations.
\end{abstract}

Keywords: early warning score; emergency medical services; patient safety; medical decision-making; critical care

\section{Introduction}

The incidence of patients with traumatic brain injury (TBI) in industrialised countries is approximately 200/100,000 inhabitants/year [1], representing one of the most common causes of permanent damage; around $10 \%-20 \%$ of cases are severe and usually require the intensive-care unit (ICU), presenting high mortality [2,3]. The current epidemiological pattern includes traffic accidents, followed by work-related accidents, falls and deliberate self-harm [4].

TBIs are complex situations that can clearly benefit from prehospital care [5]. Advanced trauma life-support actions, developed at the scene or en route, decisively contribute to avoiding brain 
injuries secondary to hypoxia or hypotension [6-8]. When dealing with TBIs in a prehospital setting, the emergency medical services (EMS) must carry out a systematised assessment [9] and must be able to perform complex procedures at the scene, such as advanced airway management, advanced immobilisation techniques, and analgesia procedures [10].

When dealing with patients with a possible TBI, the EMS must make decisions quickly with very little data. Depending on the injury mechanism, an initial systematized assessment and a few additional tests are used to decide, in line with treatment guides, the best treatment strategy for this specific situation. The early warning scores (EWS) are tools that can help the professional to make clinical decisions, predict the risk of deterioration, monitor the evolution of the patient, and facilitate communication between different levels of care, specifically to promote the safety of the patient $[11,12]$.

The use of EWS in patients with major trauma is well-documented in clinical practice [13-15]. Similarly, the Glasgow Coma Scale (GCS) is normally used to establish the severity of the TBI [16-18]. There are various scores for predicting adverse outcomes after a TBI, but they are designed for use in the emergency department (ED) and ICU $[19,20]$ where advanced diagnostic equipment is available but there are no specific scores to be used in a prehospital setting.

There is a growing interest in being able to detect bed-side those situations that require a rapid clinical response, and different EWS have been developed, used as standard in ED or ICU, but that until now had not been used in the prehospital context, to try to predict or estimate the risk of suffering serious adverse events in a TBI.

The main aim of this study is to compare the diagnostic accuracy of four EWS commonly used in a prehospital setting for the early detection of TBI to specify the need for ICU, and secondarily:

- To analyze the accuracy of the different scores for a composite outcome of prehospital serious adverse events ( $p S A E s)$, understood as the need for advanced airway management and/or mean arterial pressure below $70 \mathrm{mmHg}$ at the scene or en route. The standard protocols in the EMS for advanced airway management include orotracheal intubation, use of alternative devices for difficult airway management (laryngeal mask, video-laryngoscope, laryngeal tube, etc.) and mechanical ventilation with transport respirators. The management of hemorrhagic shock includes the use of tourniquets and hemostatic dressings for the management of external hemorrhages, and the use of vacuum splints, vacuum mattress, pelvis immobilizer, serum administration (permissive hypotension), intravenous use of tranexamic acid, fast transportation and hospital notice.

- To assess the scores for the detection of early mortality (within 48 hours of the index event for any cause in the hospital).

\section{Materials and Methods}

\subsection{Study Description and Setting}

This is a prospective, multicentric cohort study, without intervention of all TBI presenting at hospital via EMS.

The study was carried out using the Castile and Leon (Spain) EMS system between 1 October 2018 and 30 November 2019 with a reference population of 1,364,952 inhabitants. Seven advanced life-support units (ALS) were selected with attendance at an average of 4 or more incidents daily and their reference hospitals (four tertiary university hospitals and one small general district hospital).

The ALS comprise a physician, an emergency registered nurse and two emergency medical technicians performing standard advanced life support procedures at the scene and en route, according to protocols.

\subsection{Participants}

The sample was selected from among all emergency calls attended consecutively from patients aged over 18 with a prehospital diagnosis of TBI and transported with ALS selected from among all emergency calls from patients over 18 years received consecutively. 
Cases of cardiorespiratory arrest, pregnant women, patients transported on basic life support or discharged in situ were excluded. When the scene was not safe (e.g. attacks), the patient was not assessed for eligibility. Similarly, excluded from the study were those cases in which it was not possible to obtain informed consent or where the vital signs necessary to calculate the scores were not collected in full. Repeat cases were filtered and only the first event for a given patient was considered.

\subsection{Selection of Early Warning Scores}

Scores were selected that are validated, easy-to-apply in a prehospital setting and that use single parameter or multiple parameter systems, or aggregated weighting systems based on determinations of standard vital signs and/or simple clinical observations. Analysis was not performed on scores using complex parameters (e.g., analytical determinations, diuresis, anatomical injuries) such as the Sequential Organ Failure Assessment score [21] or Acute Physiology and Chronic Health Evaluation [22]. Four EWS were selected (see Appendix A Table A1) with the following validation values:

- $\quad$ National Early Warning Score 2 (NEWS2) [23], alarm triggers 7 points.

- $\quad$ Modified Early Warning Score (MEWS) [24], alarm triggers $\geq 4$ points.

- $\quad$ Triage Early Warning Score (TEWS) [25], alarm triggers 7 points.

- Modified Rapid Emergency Medicine Score (MREMS) [26], alarm triggers 14 points.

\subsection{Outcome Measures and Data Collection}

For every patient, at the scene or en route, the emergency registered nurse collected the first set of vital signs and clinical observations required to calculate the scores analyzed. The breathing rate was determined by visually observing the rising and falling of the thorax over 30 seconds; if in doubt, the breathing rate was recounted during pulmonary auscultation lasting a full minute, Oxygen saturation, heart rate and systolic arterial pressure were measured using the LifePAK®15 (Physio-Control, Inc., Redmond, WA, USA) defibrillator/monitor and the temperature with the ThermoScan $® P R O 6000$ (WelchAllyn, Inc, Skaneateles Falls, NY, USA) tympanic thermometer. In addition, the GCS was performed and the fraction of inspired oxygen (Fi02) was noted down as a percentage along with the patient's mobility (walking, with help or stretcher/immobile). To determine the blood glucose values, the FreeStyleOptium Neo device (Abbott Laboratories, Chicago, IL, USA) was used with a measuring range of $20-500 \mathrm{mg} / \mathrm{dl}$.

The physician of the ALS collected the patient's data, arrival, treatment and transport times, the demographic variables (gender, age, trauma type, injury mechanism) and the advanced life-support actions performed (orotracheal intubation, use of opioid analgesics and the use of advanced immobilization and packing techniques).

For the precise linking of the data, between the clinical history from the EMS in paper form and the electronic clinical history from the hospital (JIMENA, SACYL), date, arrival time, first name and surnames, age, gender and, if available, the healthcare card number (personal and non-transferable) were checked. 5 of 6 descriptors were necessary to guarantee the traceability of the data. Once the data had been linked, the identifiers of the patients were anonymized.

Seventy two hours after the index event, an investigator associated with each hospital reviewed the patient's electronic clinical history to record the hospital outcomes: need for admission, performance of CT scans, surgical interventions, ICU and mortality within 48 hours of the trauma for any reason in the hospital.

The data for all the patients was recorded electronically in a database created for this purpose. The GCS data was categorized in accordance with the Alert-Verbal-Pain-Unresponsive score (AVPU), alert (GCS $=14-15$ points), verbal (GCS $=11-13$ points), pain (GCS $=9-10$ points) and unresponsive (GCS $\leq 8$ points). The $\mathrm{FiO} 2$ was categorized by the use of supplemental oxygen on arrival ( $\mathrm{FiO} 2 \geq 0.22$ = supplemental oxygen). With the set of vital signs and clinical observations (obtained directly or based on calculation or recoding of other variables) required in the database, all the scores analyzed 
were calculated as well as the composite outcome of $p$ SAEs (need for advanced airway management and/or mean arterial pressure below $70 \mathrm{mmHg}$ on arrival at the ED).

\subsection{Missing Data}

By means of logical, rank and consistency tests, the database was cleaned resulting in a total of 32 variables. Then a full analysis was carried out, variable-by-variable of unknown data, only considered for the analysis of vital signs, in line with previous studies $[27,28]$. The study variables do not present lost data.

\subsection{Primary Data Analysis}

Three result variables were used, one principal (ICU) and two secondary ( $p$ SAEs and early mortality within 48 hours) and 11 independent variables (pulse, breathing rate, temperature, systolic blood pressure, oxygen saturation, supplemental oxygen, AVPU scale, mobility level, trauma injuries, GCS and age) to obtain the 4 scores analyzed (NEWS2, MEWS, TEWS and MREMS) and 14 descriptive variables (gender, arrival time, treatment and transportation, type of trauma, injury mechanism, blood sugar, orotracheal intubation, use of major analgesics, advanced immobilization and/or packing, hospital admission, computed tomography (CT) scan and surgical interventions).

All the data were recorded in a XLSTATßBioMED database for Microsoft Excel@version 14.4.0. (Microsoft Inc., Redmond, WA, USA), and SPSS version 20.0. (IBM, Armonk, NY, USA), and used to perform the subsequent statistical analysis. The data was presented in accordance with the Standards for Reporting Diagnostic Accuracy 2015 statement [29].

We calculated the area under the curve (AUC) of the receiver-operating characteristic (ROC) of the analyzed scores for $p$ SAEs, ICU and early mortality. We determined the cut-off point of each scale that offered the highest sensitivity and specificity (Youden's test), calculating in each case: positive predictive value (PPV), negative predictive value (NPV), positive probability ratio (PPR), negative probability ratio (NPR), positive likelihood ratio ( $\mathrm{LR}+$ ), negative likelihood ratio (LR-), odds ratio $(\mathrm{OR})$ and diagnostic accuracy (DA). By means of nonparametric contrasts, the equality of the AUC obtained was tested.

\subsection{Ethical Aspects}

The Research Ethics Committee of each participating institution approved the study protocol (10/2049, 10/119, MBCA/dgc, PI-18-895 and PI-010-18). All patients (or guardians) signed the informed consent. This study is reported in line with the STrengthening the Reporting of OBservational studies in Epidemiology (STROBE) statement. This study was in accordance with Good Clinical Practice and the Declaration of Helsinki.

\section{Results}

\subsection{Patients}

Our study included a total of 209 cases (Figure 1). The median age was 54 years (25th-75th percentile: $42-70$ years), 68 cases (32.5\%) were women. The most common injury mechanisms were traffic accidents ( 93 cases, $44.5 \%$ ), followed by falls (40 cases, $19.1 \%$ ) and accidents at work (26 cases, $12.4 \%)$. Table 1 shows the characteristics of the population studied.

The total number of ICU admissions was 50 cases (23.9\%), of pSAEs was 29 cases (13.9\%), and mortality within 48 hours was 11 cases (5.3\%).

The difference between patients admitted to the ICU and those not requiring ICU was significant for all the variables studied with the exception of age, breathing rate, temperature and blood glucose (Table 2). 
Patients admitted to the ICU presented a greater incidence of advanced techniques at the scene (advanced immobilization, orotracheal intubation and/or use of opioid analgesics), greater number of CT scans, surgical interventions and 20\% (10 cases) of early mortality (Table 2$)$.

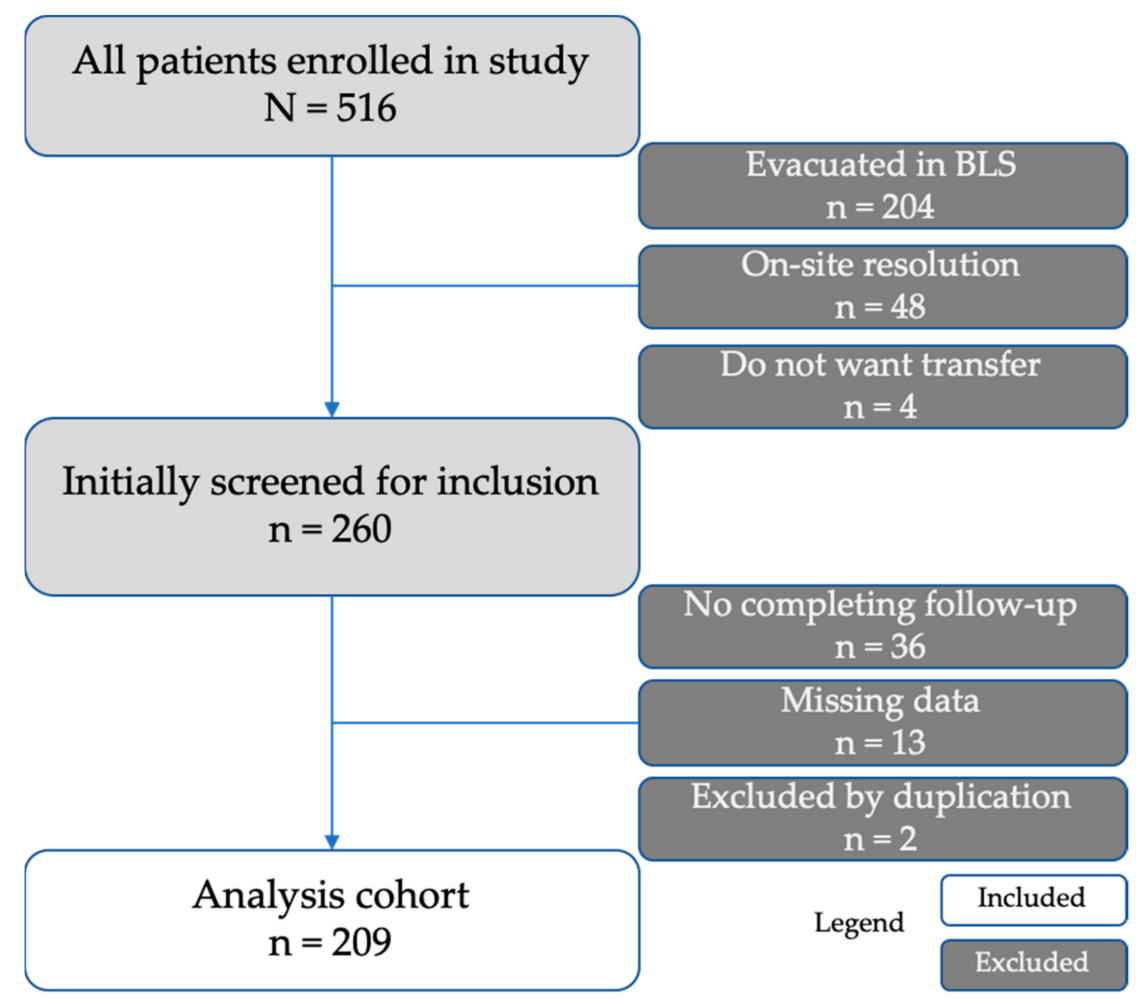

Figure 1. Study participants flowchart. BLS: basic life support

Table 1. Demographic variables (reference rates to intensive care unit inpatients).

\begin{tabular}{lcccc}
\hline & & \multicolumn{3}{c}{ Intensive-Care Unit (ICU) } \\
\cline { 3 - 5 } Variable $^{1}$ & Total & No & Yes & $p$ Value \\
\hline Number & 209 & $154(73.7)$ & $50(23.9)$ & \\
Age (years) & $54(42-70)$ & $54(40-69)$ & $55(42-74)$ & 0.469 \\
Sex (Female) & & & & 0.551 \\
$\quad$ Male & $141(67.5)$ & $109(68.6)$ & $32(64.0)$ & \\
Female & $68(32.5)$ & $50(31.4)$ & $18(36.0)$ & \\
Isochronous (minutes) & & & & \\
$\quad$ Arrival time & $9(7-14)$ & $10(7-14)$ & $9(6-15)$ & 0.698 \\
Support time & $29(22-36)$ & $27(21-34)$ & $35(25-46)$ & $<0.001$ \\
$\quad$ Transfer time & $8(11-16)$ & $10(8-16)$ & $11(8-20)$ & 0.236 \\
Injury mechanism & & & & 0.756 \\
$\quad$ Traffic accidents & $93(44.5)$ & $71(44.7)$ & $22(44.0)$ & \\
Pedestrians run over & $18(8.6)$ & $10(6.3)$ & $8(16.0)$ & \\
$\quad$ Work accidents & $26(12.4)$ & $22(13.8)$ & $4(8.0)$ & \\
$\quad$ Sports injuries & $17(8.1)$ & $13(8.2)$ & $4(8.0)$ & \\
Falls & $40(19.1)$ & $34(21.4)$ & $6(12.0)$ & \\
$\quad$ Precipitates & $9(4.3)$ & $4(2.5)$ & $5(10.0)$ & \\
$\quad$ Violence & $6(2.9)$ & $5(3.1)$ & $1(2.0)$ & \\
Injured type & $3(1.4)$ & $3(1.9)$ & & 0.330 \\
$\quad$ Penetrating & $206(98.6)$ & $156(98.1)$ & $50(100)$ & \\
$\quad$ Blunt & &
\end{tabular}

${ }^{1}$ Values expressed as total number (fraction) and medians [25th percentile-75th percentile] as appropriate. 
Table 2. Outcomes of study subjects. Reference rates to intensive-care unit inpatients.

\begin{tabular}{lccccc}
\hline & & \multicolumn{3}{c}{ Intensive-Care Unit } & \\
\cline { 3 - 5 } Variable $^{1}$ & Total & No & Yes & $p$ Value & OR $^{2}$ \\
\hline Age (years) & $54(42-70)$ & $54(40-69)$ & $55(42-74)$ & 0.469 & $1.00(0.99-1.02)$ \\
Initial evaluation & & & & & \\
$\quad$ Pulse (bpm) & $85(74-100)$ & $85(74-99)$ & $92(73-112)$ & 0.018 & $1.01(1.00-1.03)$ \\
BR (bpm) & $16(14-19)$ & $16(14-19)$ & $18(12-20)$ & 0.457 & $1.01(0.97-1.07)$ \\
T ( ${ }^{\circ}$ C) & $36.0(35.8-36.6)$ & $36.0(36.0-36.7)$ & $36.0(35.0-36.6)$ & 0.096 & $0.65(0.44-0.97)$ \\
SBP (mmHg) & $130(118-148)$ & $135(122-150)$ & $119(100-140)$ & 0.003 & $0.97(0.96-0.99)$ \\
SpO2 (\%) & $96(94-98)$ & $97(95-99)$ & $91(81-96)$ & $<0.001$ & $0.83(0.77-0.89)$ \\
Air oxygen & $65(31.3)$ & $26(16.4)$ & $39(78.0)$ & $<0.001$ & $0.05(0.02-0.12)$ \\
GCS (points) & $15(14-15)$ & $15(15-15)$ & $10(4-15)$ & $<0.001$ & $0.62(0.52-0.73)$ \\
Mobility level & & & & & \\
$\quad$ Walking & $40(19.1)$ & $38(23.9)$ & $2(4.0)$ & $<0.001$ & $2.95(1.73-5.02)$ \\
$\quad$ With help & $84(40.2)$ & $68(42.8)$ & $16(32.0)$ & & \\
$\quad$ Stretcher & $85(40.7)$ & $53(33.3)$ & $32(6040)$ & & \\
Glucose (mg/dL) & $120(101-145)$ & $120(100-140)$ & $120(101-166)$ & 0.122 & $1.00(0.99-1.01)$ \\
Prehospital outcomes & & & & & \\
Immobilization & $85(40.7)$ & $53(33.3)$ & $32(64.0)$ & 0.001 & $3.55(1.82-6.91)$ \\
Intubation & $24(11.5)$ & $1(0.6)$ & $23(46.0)$ & $<0.001$ & $134(17.4-1038)$ \\
Opioid analgesics & $85(40.7)$ & $47(29.6)$ & $38(76.0)$ & $<0.001$ & $7.54(3.62-15.7)$ \\
MAP < 70 mmHg & $14(6.7)$ & $4(2.5)$ & $10(20.0)$ & $<0.001$ & $9.68(2.88-32.5)$ \\
Hospital outcomes & & & & & \\
Inpatients & $102(48.8)$ & $52(32.7)$ & $50(100)$ & $<0.001$ & \\
CTscan & $158(75.6)$ & $110(69.2)$ & $48(96.0)$ & $<0.001$ & $10.6(2.49-45.7)$ \\
Surgery & $34(16.3)$ & $9(5.7)$ & $25(50.0)$ & $<0.001$ & $16.6(6.97-39.8)$ \\
Early mortality & $11(5.3)$ & $1(0.6)$ & $10(20.0)$ & $<0.001$ & $39.5(4.91-317)$ \\
\hline
\end{tabular}

${ }^{1}$ Values expressed as total number (fraction) and medians [25th percentile-75th percentile] as appropriate.

${ }^{2}$ Bracketed numbers indicate $95 \%$ confidence interval. ${ }^{3}$ It is not possible to calculate the Odds ratio (one of the variables has the zero's value). BR: Breathing rate; T: Temperature; SBP: Systolic blood pressure; MAP: mean arterial pressure; SpO2: Oxygen saturation; GCS: Glasgow Coma Scale.

\subsection{Prognostic Accuracy of the Scores}

The diagnostic accuracy of all the scores analyzed for the ICU requirement is shown in Figure 2a. The score with the best performance was the NEWS2 with an AUC of 0.888 (95\% confidence interval (CI) $0.81-0.94 ; p<0.001)$; the comparison of the curves presented significant differences between the NEWS2 and the other scores $(p<0.05)$, with the exception of the TEWS with which no differences were observed.

In terms of the detection of pSAEs, the score with the best result was the MEWS with an AUC of 0.923 (95\% CI: $0.85-0.99 ; p<0.001$ ) (Figure $2 b$ ). In the comparison of the curves, there were no significant differences between the four scores analyzed $(p>0.05)$. To predict early mortality (Figure $2 c)$, the score that gave the best data was also the NEWS2, with an AUC of 0.955 (95\% CI: $0.86-1.00$; $p<0.001)$ although in this case there were no statistically significant differences when comparing the curves $(p>0.05)$.

Table 3 shows the different statistics and the cut-off point with better sensitivity and specificity combined (Youden's test) for the different scores and outcomes studied. In general terms, all the scores analyzed present very high specificity for all the outcomes and specifically excellent sensitivity for the prediction of early mortality. The outcome with the most discreet results is the prediction of the need for ICU where the NEWS2 is the score that behaves better overall with a positive likelihood ratio of 7.35 (95\% CI: 4.49-12.04) and negative likelihood ratio of 0.29 (95\% CI: 0.18-0.47). 


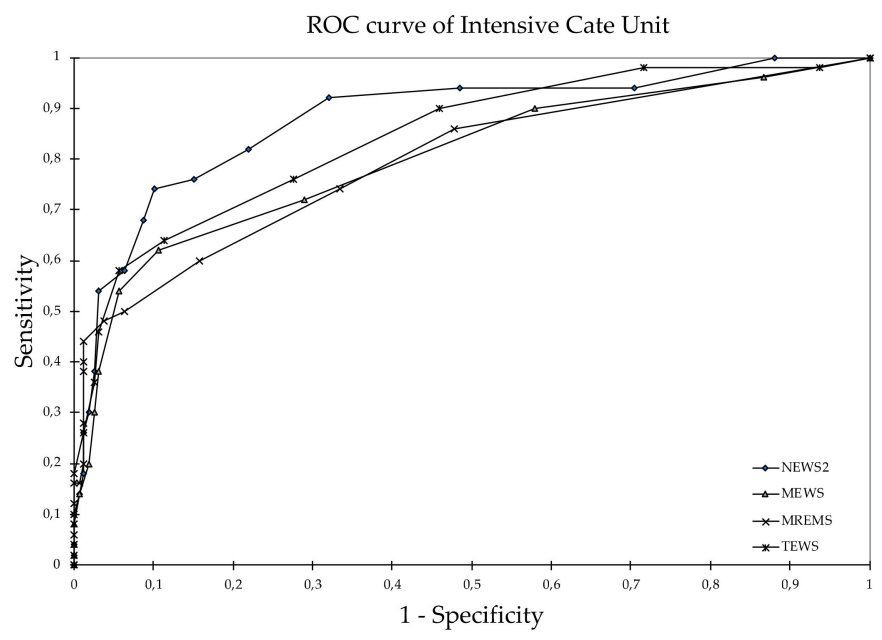

(a)

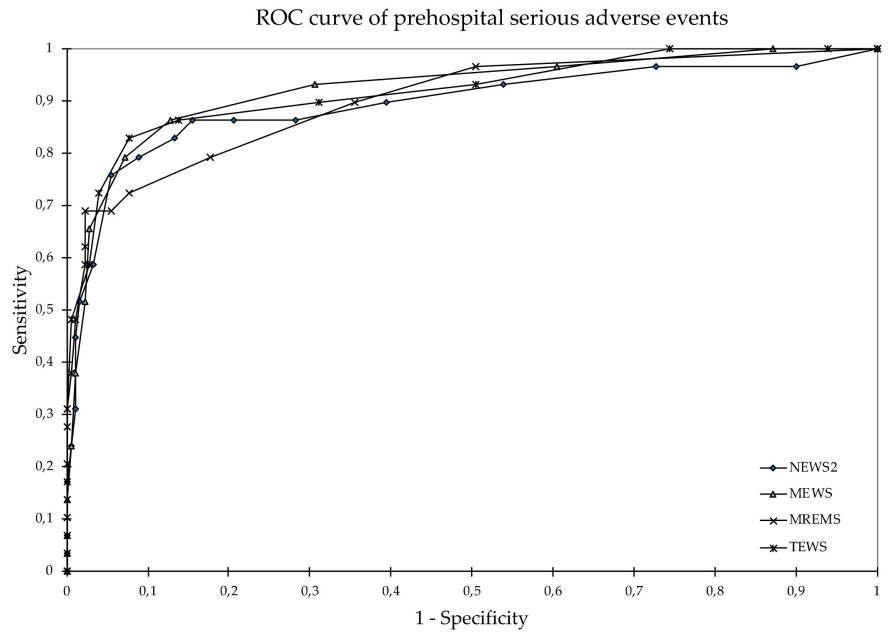

(b)

ROC curve of early mortality

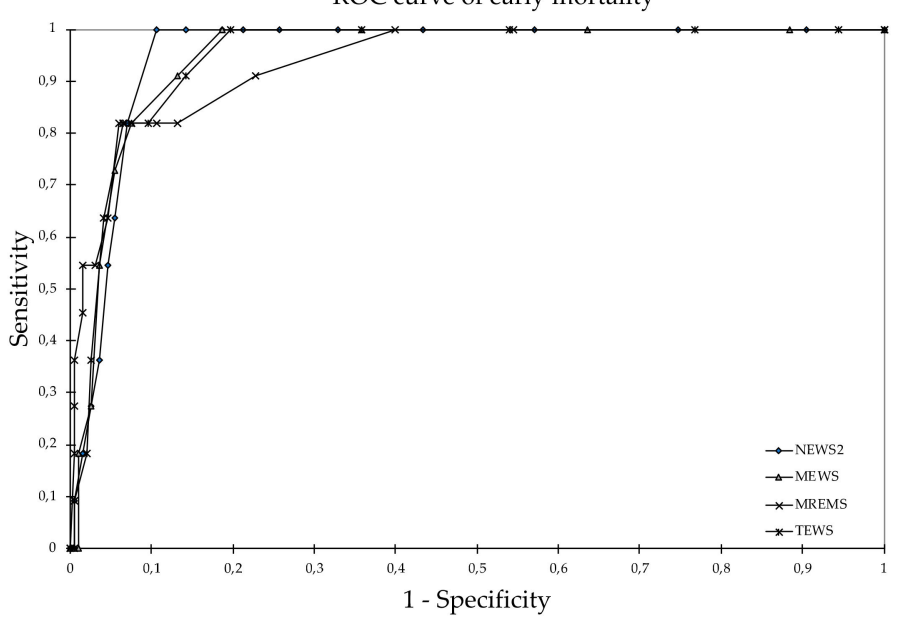

(c)

Figure 2. Diagnostic performance curves and areas under the curve: (a) Intensive care unit; (b) prehospital serious adverse events; (c) early mortality. NEWS2: National Early Warning Score 2; MEWS: Modified Early Warning Score; TEWS: Triage Early Warning Score; MREMS: Modified Rapid Emergency Medicine Score 
Table 3. AUROC, cut-off points for combined sensitivity and specificity with best score (Youden's test) to NEWS2, MEWS, TEWS and MREMS for ICU, pSAEs and early mortality.

\begin{tabular}{|c|c|c|c|c|}
\hline Score & NEWS2 $^{1}$ & MEWS $^{1}$ & TEWS $^{1}$ & MREMS $^{1}$ \\
\hline & \multicolumn{4}{|c|}{ Intensive-care unit (50 cases, $23.9 \%$ ) } \\
\hline Cut-off & 7 & 4 & 6 & 7 \\
\hline AUROC & $0.88(0.81-0.94)$ & $0.80(0.72-0.88)$ & $0.84(0.77-0.91)$ & $0.79(0.71-0.87)$ \\
\hline $\mathrm{p}$ value & $<0.001$ & $<0.001$ & $<0.001$ & $<0.001$ \\
\hline Sensitivity & $74.0(60.4-84.1)$ & $62.0(48.2-74.1)$ & $64.0(50.1-75.9)$ & $60.0(46.2-72.8)$ \\
\hline Specificity & $89.9(84.3-93.7)$ & $89.3(83.5-93.2)$ & $88.7(82.8-92.7)$ & $84.3(77.8-89.1)$ \\
\hline PPV & $69.8(56.5-80.5)$ & $64.6(50.4-76.6)$ & $64.0(50.1-75.9)$ & $54.5(41.5-67.0)$ \\
\hline NPV & $91.7(86.3-95.1)$ & $88.2(82.3-92.3)$ & $88.7(82.8-92.7)$ & $87.0(80.8-91.4)$ \\
\hline Likelihood ratio + & $7.3(4.5-12.0)$ & $5.80(3.5-9.5)$ & $5.6(3.5-9.1)$ & $3.8(2.5-5.8)$ \\
\hline Likelihood ratio - & $0.3(0.2-0.5)$ & $0.43(0.3-0.6)$ & $0.4(0.3-0.6)$ & $0.5(0.3-0.7)$ \\
\hline Odds ratio & $25.4(11.2-57.5)$ & $13.6(6.4-29.1)$ & $13.9(6.5-29.7)$ & $8.0(3.9-16.3)$ \\
\hline \multirow[t]{2}{*}{ DA } & $86.1(80.8-1)$ & $82.8(77.1-87.3)$ & $82.8(77.1-87.3)$ & $78.5(72.4-83.5)$ \\
\hline & \multicolumn{4}{|c|}{ Prehospital serious adverse events ( 29 cases, $13.9 \%$ ) } \\
\hline Cut-off & 7 & 4 & 7 & 10 \\
\hline AUROC & $0.89(0.81-0.97)$ & $0.92(0.85-0.99)$ & $0.91(0.84-0.98)$ & $0.90(0.82-0.97)$ \\
\hline$p$ value & $<0.001$ & $<0.001$ & $<0.001$ & $<0.001$ \\
\hline Sensitivity & $86.2(69.4-94.5)$ & $86.2(69.4-94.5)$ & $82.8(65.5-92.4)$ & $69.0(50.8-82.7)$ \\
\hline Specificity & $84.4(78.4-89.0)$ & $87.2(81.6-91.3)$ & $92.2(87.4-95.3)$ & $97.8(94.4-99.1)$ \\
\hline PPV & $47.2(34.4-60.3)$ & $52.1(38.3-65.5)$ & $63.2(47.2-76.6)$ & $83.3(64.1-93.3)$ \\
\hline NPV & $97.4(93.6-99.0)$ & $97.5(93.8-99.0)$ & $97.1(93.3-98.7)$ & $95.1(91.0-97.4)$ \\
\hline Likelihood ratio + & $5.5(3.8-8.0)$ & $6.7(4.5-10.1)$ & $10.6(6.2-18.1)$ & $31.0(11.4-84.3)$ \\
\hline Likelihood ratio - & $0.2(0.0-0.4)$ & $0.1(0.0-0.4)$ & $0.2(0.1-0.4)$ & $0.3(0.2-0.5)$ \\
\hline Odds ratio & $33.9(10.9-105)$ & $42.6(13.6-133)$ & $56.91(18.8-172)$ & $97.78(23.5-346)$ \\
\hline \multirow[t]{2}{*}{ DA } & $84.7(79.2-88.9)$ & $87.1(81.9-91.0)$ & $90.9(86.2-94.1)$ & $93.8(89.7-96.3)$ \\
\hline & \multicolumn{4}{|c|}{ Early mortality (11 cases, $5.3 \%$ ) } \\
\hline Cut-off & 10 & 4 & 6 & 12 \\
\hline AUROC & $0.95(0.86-1.00)$ & $0.95(0.86-1.00)$ & $0.94(0.85-1.00)$ & $0.93(0.83-1.00)$ \\
\hline $\mathrm{p}$ value & $<0.001$ & $<0.001$ & $<0.001$ & $<0.001$ \\
\hline Sensitivity & $100(74.1-100)$ & $100(74.1-100)$ & $100(74.1-100)$ & $81.8(52.3-94.9)$ \\
\hline Specificity & $89.4(84.3-93.0)$ & $81.3(75.3-86.1)$ & $80.3(74.2-85.2)$ & $93.9(89.7-96.5)$ \\
\hline PPV & $34.4(20.4-51.7)$ & $22.9(13.3-36.5)$ & $22.0(12.8-35.2)$ & $42.9(24.5-63.5)$ \\
\hline NPV & $100(97.9-100)$ & $100(97.7-100)$ & $100(97.6-100)$ & $98.9(96.2-99.7)$ \\
\hline Likelihood ratio + & $9.4(6.3-14.1)$ & $5.3(4.0-7.1)$ & $5.1(3.8-6.7)$ & $13.5(7.3-24.9)$ \\
\hline Likelihood ratio - & $0^{2}$ & $0^{2}$ & $0^{2}$ & $0.2(0.0-0.7)$ \\
\hline Odds ratio & $0^{3}$ & $0^{3}$ & $0^{3}$ & $69.7(13.5-359)$ \\
\hline DA & $90.0(85.1-93.3)$ & $82.3(76.6-86.9)$ & $81.3(75.5-86.0)$ & $93.3(89.1-96.0)$ \\
\hline
\end{tabular}

\section{Discussion}

With this preliminary, prospective, multicentric cohort study, without intervention, of adults with TBI, we assessed the prognostic accuracy of four EWS (NEWS2, MEWS, TEWS, MREMS) to determine the need for ICU and, secondarily, its ability to assess early mortality and pSAEs. In the assessment of the principal variable, it is observed that, although all the scores analysed give good results, it is the NEWS2 and the TEWS that predict admission to ICU better than the MEWS and the MREMS. However, it is apparent that all of the four scores analysed behave similarly to predict early mortality and the pSAEs assessed.

\subsection{Comparison with Previous Studies}

Works analyzing the use of EWS in a prehospital setting are numerous $[14,15,30,31]$ and more specifically concern the use of EWS in patients with trauma [32-35]. Studies that specifically analyse scores to predict the risk of deterioration in TBI are scarce. The scales most studied are the Revised 
Trauma Score [36], the GCS [16,18] and different physiological and analytical parameters [37] or scores on spinal damage [38]. Najafi et al. [39] analyzed the use of different scores to predict the risk of death within 24 hours, including the NEWS, offering our study (although with a mortality outcome within 48 hours) better AUROC, as well as better sensitivity and specificity.

\subsection{Managing Prehospital Traumatic Brain Injury (TBI)}

The identification in a prehospital setting of TBIs with a high risk of deterioration is directly influenced by the early detection of the two physio-pathological situations causing most morbimortality, hypoxia and hypotension [40,41]. Advanced airway management at the scene [42] using orotracheal intubation in those TBIs with a low GCS score, presence of convulsions, agitation, or in case of situations with other associated trauma, is a recognized practice approved by current brain injury treatment guides $[43,44]$. Similarly, the appropriate handling of hypotension from the initial moments helps to prevent secondary injuries and maintain adequate cerebral perfusion pressure $[5,45,46]$. The use of advanced measures at the scene for high-risk patients directly influences short-term (admission to ICU and early mortality) and long-term evolution (mitigation of after-effects) [47,48].

\subsection{Early Warning Scores (EWS) and Prehospital TBI}

The regular assessment of the risk of deterioration through EWS is a standard procedure in multiple clinical context the use of which is more than contrasted $[14,15,28]$ and which can help to detect patients with TBI and a high risk [49,50]. Determining which patients may be subsidiaries of advanced procedures and rapid transportation to a useful center must be a priority for the EMS [51].

Of all the EWS analyzed in this study, the NEWS2 [23] seems to be the most suitable for use in a prehospital setting. The NEWS2 is validated at prehospital level [52], its use is well-established in many clinical contexts $[30,32,39]$, it only uses standard physiological parameters that can be determined at the scene or en route and may be used in both patients with trauma and those with a medical pathology [53,54]. To be able to calculate the TEWS [25], it is necessary to know whether the patient presents a trauma or not, and the mobility level, and the MREMS [24] uses age to obtain the scoring. The MEWS [26] presented less diagnostic accuracy (statistically significant) for the detection of the need for ICU, and its use is not as established as the NEWS2. Finally, although the four EWS provide very good results, it seems that the NEWS2 has some very useful benefits for the EMS.

\subsection{Implications}

We are faced with a preliminary study that addresses the use of EWS to help with decision-making in TBI in a prehospital setting. All the scores analyzed help with the early detection of pSAEs (orotracheal intubation and hypotension), with the need for admission to ICU or to find out which patients may present early mortality, but they must be interpreted with caution. The use of EWS, specifically the NEWS2, must be a routine procedure for the EMS but should always be guided by an objective and structured full clinical assessment with treatment based on up-to-date guides for each pathology.

As shown in this study, it is clear that the EWS used in a prehospital setting are excellent tools for the early detection of serious adverse events and, therefore, act as predictors of the risk of deterioration, but prospective multicentric studies must be performed with different EMS to be able to externally validate the results presented in this study.

\subsection{Limitations}

The study has various limitations. Firstly, there may be a selection bias since only those TBI cases that, due to opportunity criteria and a specific time window, were assessed and transported using ALS were included, with cases transported using basic life support or other transport vectors not being eligible. This generated a very homogeneous cohort since all the cases were assessed by the physician at the ALS and the purpose of selecting cases was to detect those cases with a risk of deterioration. 
Secondly, early mortality (within 48 hours) was determined as one of the result outcomes but we are aware that this time limitation in the inclusion of cases is partial and it may be very interesting to study mortality rates after seven or 30 days, or even in the longer term, but the objective of this study is to analyze the influence of the procedures carried out by the EMS at the scene or en route, such that mortality after two days does not seem to be an adequate solution and this is in line with similar publications $[27,55,56]$.

Finally, the data extractors were not blinded. To minimize bias, the result outcomes were clearly defined, pSAEs (orotracheal intubation or mean arterial pressure less than $70 \mathrm{mmHg}$ ), admission to ICU and/or early mortality for any reason within the hospital and within 48 hours of the index event. All staff members were trained in correct data collection and the principal investigator made regular visits to each ALS and each hospital to review the cases and resolve any discrepancies. The principal investigator reviewed $50 \%$ of the sample.

\section{Conclusions}

To summarize, the use of EWS (and specifically NEWS2) can help the EMS to differentiate TBI patients with a high risk of deterioration. The EWS are calculated using a few parameters that are easy to obtain, non-invasive and available in a prehospital so the EMS should use the EWS routinely in all cases for the early detection of high-risk situations.

Author Contributions: Conceptualization, F.M.-R. and R.L.-I.; methodology, J.L.M.-C., A.M.-M. and B.P.-L.; software, G.M.; formal analysis, F.M.-R., J.G.C. and R.L.-I.; investigation, A.M.-M., B.P.-L., J.G.G. and C.M.M.; resources, C.M.M., A.V. and C.D.F..; data curation, C.D.F.; writing-original draft preparation, F.M.-R.; writing-review and editing, R.L.-I.; visualization, G.M.; supervision, J.L.M.-C.; project administration, X.X.; funding acquisition, F.M.-R. All authors have read and agreed to the published version of the manuscript.

Funding: This research was funded by Gerencia Regional de Salud de Castilla y León (Spain), grant number GRS 1678/A/18 and Consejería de Sanidad de Castilla y León (Spain), grant number INT/E/02/19.

Acknowledgments: The authors thank the personnel of the nursing and medical staff from ambulances and the emergency department of all hospitals, all of them belonging to the public health system of Castilla y León (SACYL), for her assistance in facilitating data collection.

Conflicts of Interest: The authors declare no conflict of interest. The funders had no role in the design of the study; in the collection, analyses, or interpretation of data; in the writing of the manuscript, or in the decision to publish the results. Sponsor's role: none.

\section{Appendix A}

Table A1. Early Warning Score (EWS) analyzed in the study.

\begin{tabular}{|c|c|c|c|c|c|c|c|}
\hline NEWS2 & 3 & 2 & 1 & 0 & 1 & 2 & 3 \\
\hline Pulse (bpm) & $\leq 40$ & & $41-50$ & $51-90$ & $91-110$ & $111-130$ & $\geq 131$ \\
\hline BR (bpm) & $\leq 8$ & & $9-11$ & $12-20$ & & $21-24$ & $\geq 25$ \\
\hline $\mathrm{T}\left({ }^{\circ} \mathrm{C}\right)$ & $\leq 35$ & & $35.1-36$ & $36.1-38$ & $38.1-39$ & $\geq 39.1$ & \\
\hline SBP (mmHg) & $\leq 90$ & $91-100$ & 101-110 & 111-219 & & & $\geq 220$ \\
\hline $\begin{array}{l}\text { SpO2 (\%) } \\
\text { Scale } 1\end{array}$ & $\leq 91$ & $92-93$ & 94-95 & $\geq 96$ & & & \\
\hline $\mathrm{SpO} 2(\%)$ & & & & $88-92$ & 93-94 & $95-96$ & $\geq 97$ \\
\hline Scale $2^{1}$ & $\leq 83$ & $84-85$ & $86-87$ & $\geq 93$ air & Oxygen & Oxygen & Oxygen \\
\hline Air oxygen & & Oxygen & & Air & & & \\
\hline AVPU (scale) & & & & A & & & $\mathrm{V}, \mathrm{P}, \mathrm{U}$ \\
\hline MEWS & 3 & 2 & 1 & 0 & 1 & 2 & 3 \\
\hline Pulse (bpm) & & $\leq 40$ & $41-50$ & 51-100 & $101-110$ & $111-129$ & $\geq 130$ \\
\hline $\mathrm{BR}(\mathrm{bpm})$ & & $<9$ & & 9-14 & 15-20 & $21-29$ & $\geq 30$ \\
\hline $\mathrm{T}\left({ }^{\circ} \mathrm{C}\right)$ & & $\leq 35$ & $35.1-36$ & $36.1-38$ & $38.1-38.5$ & $>38.5$ & \\
\hline SBP (mmHg) & $\leq 70$ & $71-80$ & $81-100$ & 101-199 & & $\geq 200$ & \\
\hline AVPU (scale) & & & & A & V & $\mathrm{P}$ & U \\
\hline
\end{tabular}


Table A1. Cont.

\begin{tabular}{|c|c|c|c|c|c|c|c|}
\hline TEWS & 3 & 2 & 1 & 0 & 1 & 2 & 3 \\
\hline Pulse (bpm) & & $\leq 40$ & $41-50$ & $51-100$ & $101-110$ & 111-130 & $>130$ \\
\hline BR (bpm) & & $\leq 8$ & & $9-20$ & & $21-30$ & $>30$ \\
\hline $\mathrm{T}\left({ }^{\circ} \mathrm{C}\right)$ & $\leq 35$ & & $35-38.1$ & & $>38.4$ & & \\
\hline $\mathrm{SBP}(\mathrm{mmHg})$ & $\leq 70$ & $71-80$ & $81-100$ & 101-139 & 140-199 & $>199$ & \\
\hline AVPU (scale) & & & & A & $\mathrm{V}$ & $\mathrm{P}$ & $\mathrm{U}$ \\
\hline Mobility level & & & & Walking & With help & Stretcher Immobile & \\
\hline Trauma & & & & No & Yes & & \\
\hline MREMS & 0 & 1 & 2 & 3 & 4 & 5 & 6 \\
\hline Pulse (bpm) & 70-109 & & $\begin{array}{c}55-69 \\
110-139\end{array}$ & $\begin{array}{c}40-54 \\
140-179\end{array}$ & $\begin{array}{c}<39 \\
>179\end{array}$ & & \\
\hline BR (bpm) & $12-24$ & $\begin{array}{l}10-11 \\
25.34\end{array}$ & $6-9$ & $35-49$ & $\begin{array}{c}<5 \\
>49\end{array}$ & & \\
\hline SBP (mmHg) & 70-109 & & $\begin{array}{c}50-69 \\
110-129\end{array}$ & 130-159 & $\begin{array}{l}\leq 49 \\
>159\end{array}$ & & \\
\hline SpO2 (\%) & $>89$ & $88-89$ & & $75-85$ & $<75$ & & \\
\hline GCS (scale) & $14-15$ & $11-13$ & $8-10$ & $5-7$ & $3-4$ & & \\
\hline Age (years old) & $<45$ & & $45-54$ & $55-64$ & & 65-74 & $>74$ \\
\hline
\end{tabular}

${ }^{1}$ In patients with hypercapnic respiratory insufficiency, scale 2 should be used to weight the oxygen saturation score. SBP: Systolic blood pressure; BR: Breathing rate; SpO2: Oxygen saturation; AVPU: alert, verbal, pain, unresponsive: T: temperature; GCS: Glasgow coma scale; NEWS2: National Early Warning Score 2; MEWS: Modified Early Warning Score; TEWS: Triage Early Warning Score; MREMS: Modified Rapid Emergency Medicine Score.

\section{References}

1. Ortega Zufiría, J.M.; Lomillos Prieto, N.; Choque Cuba, B.; Tamarit Degenhardt, M.; Poveda Núñez, P.; López Serrano, M.R.; López Raigada, A.B. Mild head injury. Surg. Neurol. 2018, 9, S16-S28.

2. Voss, J.D.; Connolly, J.; Schwab, K.A.; Scher, A.I. Update on the epidemiology of concussion/mild traumatic brain injury. Curr. Pain Headache Rep. 2015, 19, 32. [CrossRef] [PubMed]

3. Harmsen, A.M.K.; Giannakopoulos, G.F.; Moerbeek, P.R.; Jansma, E.P.; Bonjer, H.J.; Bloemers, F.W. The influence of prehospital time on trauma patient's outcome: A systematic review. Injury 2015, 46, 602-609. [CrossRef] [PubMed]

4. Juelsgaard, J.; Rognås, L.; Knudsen, L.; Hansen, T.M.; Rasmussen, M. Prehospital treatment of patients with acute intracranial pathology: Adherence to guidelines and blood pressure recommendations by the Danish air ambulance. Scand. J. Trauma Resusc. Emerg. Med. 2018, 26, 68. [CrossRef] [PubMed]

5. $\quad$ Denninghoff, K.R.; Nuño, T.; Pauls, Q.; Yeatts, S.D.; Silbergleit, R.; Palesch, Y.Y.; Merck, L.H.; Manley, G.T.; Wright, D.W. Prehospital intubation is associated with favorable outcomes and lower mortality in ProTECT III. Prehosp. Emerg. Care 2017, 21, 539-544. [CrossRef]

6. Joseph, B.; Pandit, V.; Zangbar, B.; Kulvatunyou, N.; Khalil, M.; Tang, A.; O’Keeffe, T.; Gries, L.; Vercruysse, G.; Friese, R.S.; et al. Secondary brain injury in trauma patients: The effects of remote ischemic conditioning. J. Trauma Acute Care Surg. 2015, 78, 698-703. [CrossRef]

7. Teuben, M.; Löhr, N.; Jensen, K.O.; Brüesch, M.; Müller, S.; Pfeifer, R.; Mica, L.; Pape, H.C.; Sprengel, K. Improved pre-hospital care efficiency due to the implementation of pre-hospital trauma life support (PHTLS) algorithms. Eur. J. Trauma Emerg. Surg. 2019. [CrossRef]

8. Pakkanen, T.; Nurmi, J.; Huhtala, H.; Silfvast, T. Prehospital on-scene anaesthetist treating severe traumatic brain injury patients is associated with lower mortality and better neurological outcome. Scand. J. Trauma Resusc. Emerg. Med. 2019, 27, 9. [CrossRef]

9. Pourahmad, S.; Rasouli-Emadi, S.; Moayyedi, F.; Khalili, H. Comparison of four variable selection methods to determine the important variables in predicting the prognosis of traumatic brain injury patients by support vector machine. J. Res. Med. Sci. 2019, 24, 97.

10. Kavi, T.; Abdelhady, A.; DeChiara, J.; Lubas, E.; Abdelhady, K.; Daci, R.; San Roman, J.; Patel, U.K. Association of patterns of mild traumatic brain injury with neurologic deterioration: Experience at a level I trauma center. Cureus 2019, 11, e5677. [CrossRef]

11. Barker, R.O.; Stocker, R.; Russell, S.; Roberts, A.; Kingston, A.; Adamson, J.; Hanratty, B. Distribution of the National Early Warning Score (NEWS) in care home residents. Age Ageing 2019, 49, 141-145. [CrossRef] [PubMed] 
12. Stanley, A.; Buhler, H.; Hobbs, B.; Kornelsen, J.; Lamont, S.; Kaus, R.; Grant, K.; Grzybowski, S. Standardised early warning scores in rural interfacility transfers: A pilot study into their potential as a decision-making aid. Can. J. Rural Med. 2019, 24, 83-91. [PubMed]

13. Jiang, X.; Jiang, P.; Mao, Y. Performance of Modified Early Warning Score (MEWS) and Circulation, Respiration, Abdomen, Motor, and Speech (CRAMS) score in trauma severity and in-hospital mortality prediction in multiple trauma patients: A comparison study. Peer] 2019, 7, e7227. [CrossRef] [PubMed]

14. Kramer, A.A.; Sebat, F.; Lissauer, M. A review of early warning systems for prompt detection of patients at risk for clinical decline. J. Trauma Acute Care Surg. 2019, 87, S67-S73. [CrossRef] [PubMed]

15. Pirneskoski, J.; Kuisma, M.; Olkkola, K.T.; Nurmi, J. Prehospital national early warning score predicts early mortality. Acta Anaesthesiol. Scand. 2019, 63, 676-683. [CrossRef] [PubMed]

16. Chou, R.; Totten, A.M.; Carney, N.; Dandy, S.; Fu, R.; Grusing, S.; Pappas, M.; Wasson, N.; Newgard, C.D. Predictive utility of the total glasgow coma scale versus the motor component of the glasgow coma scale for identification of patients with serious traumatic injuries. Ann. Emerg. Med. 2017, 70, 143-157. [CrossRef]

17. Bendinelli, C.; Ku, D.; King, K.L.; Nebauer, S.; Balogh, Z.J. Trauma patients with prehospital glasgow coma scale less than nine: Not a homogenous group. Eur. J. Trauma Emerg. Surg. 2019. [CrossRef]

18. Gang, M.C.; Hong, K.J.; Shin, S.D.; Song, K.J.; Ro, Y.S.; Kim, T.H.; Park, J.H.; Jeong, J. New prehospital scoring system for traumatic brain injury to predict mortality and severe disability using motor Glasgow Coma Scale, hypotension, and hypoxia: A nationwide observational study. Clin. Exp. Emerg. Med. 2019, 6, 152-159. [CrossRef]

19. Pargaonkar, R.; Kumar, V.; Menon, G.; Hegde, A. Comparative study of computed tomographic scoring systems and predictors of early mortality in severe traumatic brain injury. J. Clin. Neurosci. 2019, 66, 100-106. [CrossRef]

20. Haghbayan, H.; Boutin, A.; Laflamme, M.; Lauzier, F.; Shemilt, M.; Moore, L.; Zarychanski, R.; Douville, V.; Fergusson, D.; Turgeon, A.F. The prognostic value of MRI in moderate and severe traumatic brain injury: A systematic review and meta-analysis. Crit. Care Med. 2017, 45, e1280-e1288. [CrossRef]

21. De Grooth, H.J.; Geenen, I.L.; Girbes, A.R.; Vincent, J.L.; Parienti, J.J.; Oudemans-van Straaten, H.M. SOFA and mortality endpoints in randomized controlled trials: A systematic review and meta-regression analysis. Crit. Care 2017, 21, 38. [CrossRef] [PubMed]

22. Jeong, H.; Jung, Y.S.; Suh, G.J.; Kwon, W.Y.; Kim, K.S.; Kim, T.; Shin, S.M.; Kang, M.W.; Lee, M.S. Emergency physician-based intensive care unit for critically ill patients visiting emergency department. Am. J. Emerg. Med. 2019. [CrossRef] [PubMed]

23. Royal College of Physicians. National Early Warning Score (NEWS) 2: Standardising the Assessment of Acute-Illness Severity in the NHS; RCP: London, UK, 2017.

24. Burger, D.; Jordan, S.; Kyriacos, U. Validation of a modified early warning score-linked Situation-BackgroundAssessment-Recommendation communication tool: A mixed methods study. J. Clin. Nurs. 2017, 26, 2794-2806. [CrossRef] [PubMed]

25. Lee, S.B.; Kim, D.H.; Kim, T.; Kang, C.; Lee, S.H.; Jeong, J.H.; Kim, S.C.; Park, Y.J.; Lim, D. Triage in Emergency Department Early Warning Score (TREWS) is predicting in-hospital mortality in the emergency department. Am. J. Emerg. Med. 2019. [CrossRef] [PubMed]

26. Gök, R.G.Y.; Gök, A.; Bulut, M. Assessing prognosis with modified early warning score, rapid emergency medicine score and worthing physiological scoring system in patients admitted to intensive care unit from emergency department. Int. Emerg. Nurs. 2019, 43, 9-14. [CrossRef] [PubMed]

27. Nannan Panday, R.S.; Minderhoud, T.C.; Alam, N.; Nanayakkara, P.W.B. Prognostic value of early warning scores in the emergency department (ED) and acute medical unit (AMU): A narrative review. Eur. J. Intern. Med. 2017, 45, 20-31. [CrossRef] [PubMed]

28. Pimentel, M.A.F.; Redfern, O.C.; Gerry, S.; Collins, G.S.; Malycha, J.; Prytherch, D.; Schmidt, P.E.; Smith, G.B.; Watkinson, P.J. A comparison of the ability of the national early warning score and the national early warning score 2 to identify patients at risk of in-hospital mortality: A multi-centre database study. Resuscitation 2019, 134, 147-156. [CrossRef]

29. Bossuyt, P.M.; Cohen, J.F.; Gatsonis, C.A.; Korevaar, D.A. STARD 2015: Updated reporting guidelines for all diagnostic accuracy studies. Ann. Transl. Med. 2016, 4, 85. 
30. Hoikka, M.; Silfvast, T.; Ala-Kokko, T.I. Does the prehospital national early warning score predict the short-term mortality of unselected emergency patients? Scand. J. Trauma Resusc. Emerg. Med. 2018, 26, 48. [CrossRef]

31. Martín-Rodríguez, F.; Castro-Villamor, M.Á.; Del Pozo Vegas, C.; Martín-Conty, J.L.; Mayo-Iscar, A.; Delgado Benito, J.F.; Del Brio Ibañez, P.; Arnillas-Gómez, P.; Escudero-Cuadrillero, C.; López-Izquierdo, R. Analysis of the early warning score to detect critical or high-risk patients in the prehospital setting. Intern. Emerg. Med. 2019, 14, 581-589. [CrossRef]

32. Tirkkonen, J.; Karlsson, S.; Skrifvars, M.B. National early warning score (NEWS) and the new alternative SpO scale during rapid response team reviews: A prospective observational study. Scand. J. Trauma Resusc. Emerg. Med. 2019, 27, 111. [CrossRef] [PubMed]

33. Rocha, T.F.D. Modified early warning score: Evaluation of trauma patients. Rev. Bras. Enferm. 2016, 69, 906-911. [CrossRef] [PubMed]

34. Torun, G.; Durak, V.A. The predictive value of Triage Early Warning Score (TEWS) on mortality of trauma patients presenting to the emergency department. Ann. Ital. Chir. 2019, 90, 152-156. [PubMed]

35. Negrin, L.L.; Antoni, A.; Hajdu, S.; Heinz, T. A novel approach to identify polytraumatized patients in extremis. BioMed Res. Int. 2018, 2018, 73201. [CrossRef] [PubMed]

36. Manoochehry, S.; Vafabin, M.; Bitaraf, S.; Amiri, A. A comparison between the ability of revised trauma score and Kampala trauma score in predicting mortality; a meta-analysis. Arch. Acad. Emerg. Med. 2019, 7, e6. [PubMed]

37. Wijayatilake, D.S.; Jigajinni, S.V.; Sherren, P.B. Traumatic brain injury: Physiological targets for clinical practice in the prehospital setting and on the Neuro-ICU. Curr. Opin. Anaesthesiol. 2015, 28, 517-524. [CrossRef] [PubMed]

38. Ahmed, W.A.; Rouse, A.; Griggs, K.E.; Collett, J.; Dawes, H. Poor specificity of National Early Warning Score (NEWS) in spinal cord injuries (SCI) population: A retrospective cohort study. Spinal Cord 2019. [CrossRef]

39. Najafi, Z.; Zakeri, H.; Mirhaghi, A. The accuracy of acuity scoring tools to predict 24-h mortality in traumatic brain injury patients: A guide to triage criteria. Int. Emerg. Nurs. 2018, 36, 27-33. [CrossRef]

40. Spaite, D.W.; Hu, C.; Bobrow, B.J.; Chikani, V.; Sherrill, D.; Barnhart, B.; Gaither, J.B.; Denninghoff, K.R.; Viscusi, C.; Mullins, T.; et al. Pressure in patients with major traumatic brain injury: Implications for the hypotension threshold. JAMA Surg. 2017, 152, 360-368. [CrossRef]

41. Spaite, D.W.; Hu, C.; Bobrow, B.J.; Chikani, V.; Barnhart, B.; Gaither, J.B.; Denninghoff, K.R.; Adelson, P.D.; Keim, S.M.; Viscusi, C.; et al. The effect of combined out-of-hospital hypotension and hypoxia on mortality in major traumatic brain injury. Ann. Emerg. Med. 2017, 61, 62-72. [CrossRef]

42. Gamberini, L.; Baldazzi, M.; Coniglio, C.; Gordini, G.; Bardi, T. Prehospital airway management in severe traumatic brain injury. Air Med. J. 2019, 38, 366-373. [CrossRef] [PubMed]

43. Garvin, R.; Mangat, H.S. Emergency neurological life support: Severe traumatic brain injury. Neurocrit. Care 2017, 27, 159-169. [CrossRef] [PubMed]

44. Marehbian, J.; Muehlschlegel, S.; Edlow, B.L.; Hinson, H.E.; Hwang, D.Y. Medical management of the severe traumatic brain injury patient. Neurocrit. Care 2017, 27, 430-446. [CrossRef] [PubMed]

45. Pélieu, I.; Kull, C.; Walder, B. Prehospital and emergency care in adult patients with acute traumatic brain injury. Med. Sci. (Basel) 2019, 7, E12. [CrossRef]

46. Ram, K.; VaraPrasad, K.; Krishna, M.K.; Kannan, N.; Sundar, V.; Joseph, M.; Sinha, V.D.; Shukla, D.; Gururaj, G.; Narayan, R.K.; et al. Prehospital factors associated with discharge outcomes: Baseline data from the andhra pradesh traumatic brain injury project. World Neurosurg. X 2019, 2, 10002. [CrossRef]

47. Meizoso, J.P.; Valle, E.J.; Allen, C.J.; Ray, J.J.; Jouria, J.M.; Teisch, L.F.; Shatz, D.V.; Namias, N.; Schulman, C.I.; Proctor, K.G. Decreased mortality after prehospital interventions in severely injured trauma patients. J. Trauma Acute Care Surg. 2015, 79, 227-231. [CrossRef]

48. Valentin, G.; Jensen, L.G. What is the impact of physicians in prehospital treatment for patients in need of acute critical care? An overview of reviews. Int. J. Technol. Assess. Health Care 2019, 35, 27-35. [CrossRef]

49. Strnad, M.; Borovnik Lesjak, V.; Vujanović, V.; Križmarić, M. Predictors of mortality in patients with isolated severe traumatic brain injury. Wien. Klin. Wochenschr. 2017, 129, 110-114. [CrossRef]

50. Scheetz, L.J.; Horst, M.A.; Arbour, R.B. Early neurological deterioration in older adults with traumatic brain injury. Int. Emerg. Nurs. 2018, 37, 29-34. [CrossRef] 
51. Prabhakaran, K.; Petrone, P.; Lombardo, G.; Stoller, C.; Policastro, A.; Marini, C.P. Mortality rates of severe traumatic brain injury patients: Impact of direct versus nondirect transfers. J. Surg. Res. 2017, 219, 66-71. [CrossRef]

52. Silcock, D.J.; Corfield, A.R.; Gowens, P.A.; Rooney, K.D. Validation of the national early warning score in the prehospital setting. Resuscitation 2015, 89, 31-35. [CrossRef] [PubMed]

53. Farenden, S.; Gamble, D.; Welch, J. Impact of implementation of the national early warning score on patients and staff. Br. J. Hosp. Med. (Lond.) 2017, 78, 132-136. [CrossRef] [PubMed]

54. Faisal, M.; Richardson, D.; Scally, A.; Howes, R.; Beatson, K.; Mohammed, M. Performance of externally validated enhanced computer-aided versions of the national early warning score in predicting mortality following an emergency admission to hospital in England: A cross-sectional study. BMJ Open 2019, 9, e0315. [CrossRef] [PubMed]

55. Ehara, J.; Hiraoka, E.; Hsu, H.; Yamada, T.; Homma, Y.; Fujitani, S. The effectiveness of a national early warning score as a triage tool for activating a rapid response system in an outpatient setting. Medicine (Baltim.) 2019, 98, e1847. [CrossRef] [PubMed]

56. Patel, R.; Nugawela, M.D.; Edwards, H.B.; Richards, A.; Le Roux, H.; Pullyblank, A.; Whiting, P. Can early warning scores identify deteriorating patients in pre-hospital settings? A systematic review. Resuscitation 2018, 132, 101-111. [CrossRef] [PubMed]

(C) 2020 by the authors. Licensee MDPI, Basel, Switzerland. This article is an open access article distributed under the terms and conditions of the Creative Commons Attribution (CC BY) license (http://creativecommons.org/licenses/by/4.0/). 